\title{
Application of direct MRAC in PI controller for DC-DC boost converter
}

Lunde Ardhenta, Ramadhani Kurniawan Subroto

Department of Electrical Engineering, Brawijaya University, Indonesia

\begin{tabular}{|c|c|}
\hline Article Info & ABSTRACT \\
\hline Article history: & Almost all electronic components require a DC power supply at present days. \\
\hline Pocoived Ju1 272010 & The needs of DC power supplies from low voltage scales, medium voltages \\
\hline Received Jul 27, 2019 & such as generators, to high voltage scales for high voltage electricity \\
\hline Revised Oct 22, 2019 & transmission. The improvement of PI controller performances is presented in \\
\hline Accepted Jan 9, 2020 & $\begin{array}{l}\text { this paper. The adaptation gains improve transient response of DC-DC Boost } \\
\text { Converter several operating conditions. Massachusetts Institute of }\end{array}$ \\
\hline Keywords: & $\begin{array}{l}\text { Technology (MIT) rule is applied as an adaptive mechanism to determine the } \\
\text { optimal control parameters in some conditions. The used adaptive control }\end{array}$ \\
\hline Boost Converter & technique is Direct Model Reference Adaptive Control (MRAC), this method \\
\hline & method has a stable response and able to reach the model reference smoothly. \\
\hline DMRAC & However, the response of the system has instantaneously overshoot and \\
\hline Adaptation Gain & $\begin{array}{l}\text { follows the response back of model reference. The responses of proposed } \\
\text { controller have short period of rise time, settling time, and overshoot. }\end{array}$ \\
\hline
\end{tabular}

This is an open access article under the CC BY-SA license.

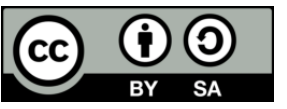

\section{Corresponding Author:}

Lunde Ardhenta, Department of Electrical Engineering, Brawijaya University

MT Haryono St. 167 Malang, Indonesia

Email: lunde.ardhenta@ub.ac.id

\section{INTRODUCTION}

Nowadays, the high efficiency is suitable to build the electronic devices and power converter has an important role in this system. The stepped up or down DC voltage is the purpose of power converter, even though using a transformer are commonly used in AC voltage. A conventional power converter still an option in industry such as industry of battery charger, uninterrupted power supplies, and other energy conversion systems [1-7].

It is required electronic components to reach the desired voltage. Recent power converter components have high quality and high efficiency. One of them is DC-DC boost converter which have utilization to step the output voltage up $[8,9]$. In order to create the DC-DC boost converter rapid changes of rensponse, it must work in high frequency $[10,11]$. In this condition, DC-DC boost converter requires controller to manage the desired value.

Adaptive controls are widely used by researchers to solve dynamic problems [12-18] and some of them use PID as its control structure. Conventional PID is based on a mathematical model, such that it has stability, reliability and control capabilities. Conventional PID controllers are effective in linear systems, but it is not suitable for non-linear systems and high-order systems. Determination of PID parameters has been used in many ways [19]. Several methods have their own advantages and drawbacks to determine PID parameters for reaching stable system. The fixed parameter in PID controller is not quite robust or not able to adapt and therefore the adaptive controller techniques is required improve system response [20, 21]. Several 
adaptive control techniques are employed to fix this problem and one of them use Direct Model Reference Adaptive Control (DMRAC) [22, 23]. DMRAC performances are provided by model as reference, it means the plant response must follow model response. The following parameter adjustment mechanism is calculated by using Massachusetts Institute of Technology (MIT) rule [24, 25]. In order to find out the response of boost converter as a non-linear system, the paper offers DMRAC in PI controller as an alternative controller to compensate for input voltage variations.

\section{PROPOSED METHOD} DMRAC.

This section describes a DC-DC boost converter model and derivation of adaptation gain using

\subsection{DC-DC Boost Converter Model}

DC-DC boost converter is commonly used in DC system and also known as step up DC converter. It has simple configuration and one of non-isolated power converter as shown in Figure 1. The output voltage demand must be greater than the input voltage and continuous. It utilizes two semiconductors such as a controlled power device, and an uncontrolled device. They consist basically of an inductor in series and capacitor in parallel.

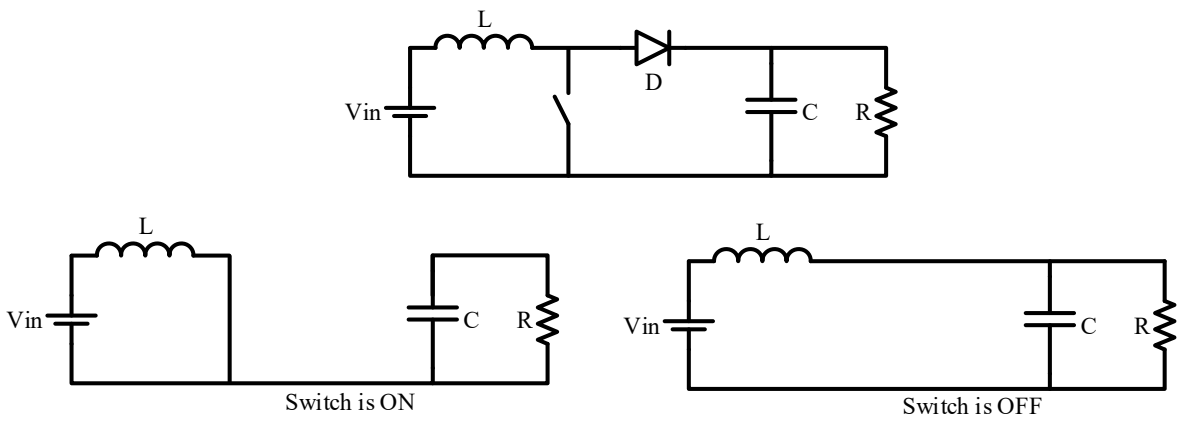

Figure 1. DC-DC boost converter states; switch ON and switch OFF

The current of inductor $i_{L}$ and voltage of capacitor $v_{C}$ are the main parameters. During the switch is ON, equation (1) specify $i_{L}$ and (2) is derived to obtain ${ }^{v_{C}}$.

$$
\begin{aligned}
& V_{\text {in }}=L \frac{d i_{L}}{d t} \\
& 0=C \frac{d v_{C}}{d t}+\frac{v_{C}}{R}
\end{aligned}
$$

During the switch is OFF, the inductor releases the charge to the capacitor and load. The condition of $v_{C}$ is defined in (3) and $i_{L}$ can be showed in (4).

$$
\begin{aligned}
& v_{c}=V_{i n}-L \frac{d i_{L}}{d t} \\
& i_{L}=C \frac{d v_{C}}{d t}+\frac{v_{C}}{R}
\end{aligned}
$$

According to the $\mathrm{ON}$ and OFF state, the average value of model for boost converter is shown in state space as (5). 


$$
\left[\begin{array}{c}
\frac{d i_{L}}{d t} \\
\frac{d v_{C}}{d t}
\end{array}\right]=\left[\begin{array}{cc}
0 & -\frac{(1-d)}{L} \\
\frac{(1-d)}{C} & -\frac{(1-d)}{R C}
\end{array}\right]\left[\begin{array}{c}
i_{L} \\
v_{C}
\end{array}\right]+\left[\begin{array}{c}
\frac{1}{L} \\
0
\end{array}\right] V_{\text {in }}
$$

In order to define the small signal model of boost converter, substituting every variable is required. Each parameter is presented in steady state part and small signal variation as follows,

$$
\begin{aligned}
& d=D+\hat{d} \\
& i_{L}=I_{L}+\hat{i}_{L} \\
& v_{c}=V_{c}+\hat{v}_{c} \\
& v_{i n}=V_{i n}+\hat{v}_{i n} \\
& L \frac{d\left(I_{L}+\hat{i}_{L}\right)}{d t}=\left(V_{i n}+\hat{v}_{i n}\right)-(1-D-\hat{d})\left(V_{c}+\hat{v}_{c}\right) \\
& C \frac{d\left(V_{c}+\hat{v}_{c}\right)}{d t}=-(1-D-\hat{d})\left(I_{L}+\hat{i}_{L}\right)-\frac{\left(V_{c}+\hat{v}_{c}\right)}{R}
\end{aligned}
$$

The steady state variables become zero by deriving these terms and the multiplication results of small signal variation are neglected. The small signal model for inductor current and capacitor voltage of boost converter as given by (8).

$$
\begin{aligned}
& \frac{d \hat{i}_{L}}{d t}=\frac{\hat{d} V_{c}+\hat{v}_{i n}-(1-D) \hat{v}_{c}}{L} \\
& \frac{d \hat{v}_{c}}{d t}=\frac{(1-D) \hat{i}_{L}-\hat{d} I_{L}}{C}-\frac{\hat{v}_{c}}{R C}
\end{aligned}
$$

The derived transfer function (9) from the output voltage to the duty cycle shows the effect of the duty cycle modify the capacitor voltage when the duty cycle performs.

$$
\frac{\hat{v}_{c}(s)}{\hat{d}(s)}=\frac{(1-D) V_{c}-L I_{L} s}{L C s^{2}+\frac{L}{R} s+(1-D)^{2}}
$$

\subsection{Direct Model Reference Adaptive Control with PI Controller}

Adaptive control system is a control system that has adjusted control parameters according to some disturbances. In DMRAC, the desired system performance is stated in a reference model. Figure 2 shows the block diagram of the DMRAC. The control parameters are changed based on error feedback, which is the difference between the output system and the output of reference model. The structure of DMRAC is divided in two loops, the inner loop and outer loop. The PI controller is employed in this research because the structure of PI controller is simple to execute in implementation. PI controller is one of single input single output (SISO) method, this controller has no ability to follow the diversity of environment. 


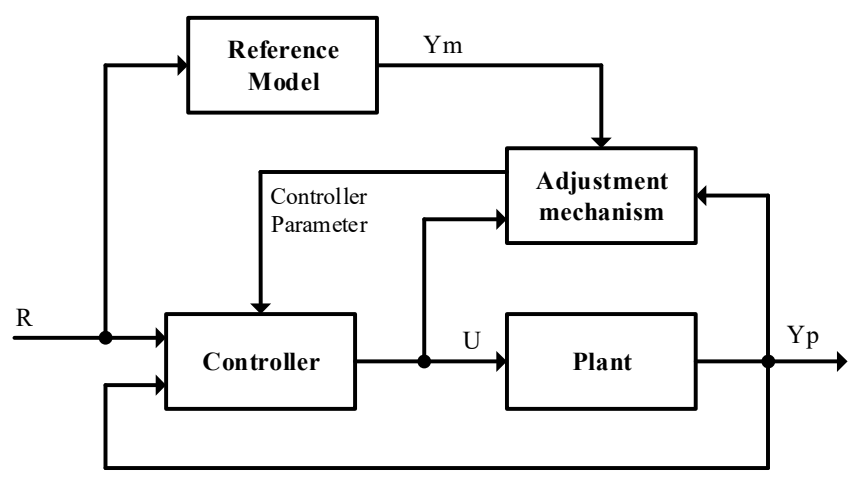

Figure 2. Direct model reference adaptive control

The boost converter is 2 nd order system, such that the described system by 2 nd order model as:

$\frac{Y_{p}(s)}{U(s)}=\frac{-b_{1} s+b_{2}}{s^{2}+a_{1} s+a_{2}}$

The reference model in 2nd order system given by:

$\frac{Y_{m}(s)}{U(s)}=\frac{b m_{1} s^{2}+b m_{2} s+b m_{3}}{s^{3}+a m_{1} s^{2}+a m_{2} s+a m_{3}}$

The term of PI controller as:

$\frac{U(s)}{R(s)-Y_{p}(s)}=K_{p}+\frac{K_{i}}{s}$

Transfer function of boost converter and PI controller is

$\frac{Y_{p}(s)}{R(s)}=\frac{\left(b_{1} s+b_{2}\right)\left(K_{p} s+K_{i}\right)}{s\left(s^{2}+a_{1} s+a_{2}\right)+\left(b_{1} s+b_{2}\right)\left(K_{p} s+K_{i}\right)}$

And

$Y_{p}(s)=\frac{\left(b_{1} s+b_{2}\right)\left(K_{p} s+K_{i}\right)}{s\left(s^{2}+a_{1} s+a_{2}\right)+\left(b_{1} s+b_{2}\right)\left(K_{p} s+K_{i}\right)} R(s)$

The difference between the output system and reference model:

$\varepsilon=Y_{p}-Y_{m}$

The form of cost function is chosen by:

$J(\theta)=\frac{1}{2} \varepsilon^{2}(\theta)$ 
Where $\varepsilon$ indicates the error between plant output and model reference output. The $\theta_{\text {has no fix }}$ value and it is set in such a way such that $J$ is minimized to zero. In MIT rule, Negative gradient of $J$ is needed to determine time rate of change of $\theta$ as shown in (17).

$$
\begin{aligned}
& \frac{d \theta}{d t}=-\gamma \frac{\partial J}{\partial \theta}=-\gamma \varepsilon \frac{\partial \varepsilon}{\partial \theta} \\
& \frac{d K_{p}}{d t}=-\gamma_{p} \frac{\partial J}{\partial K_{p}}=-\gamma \frac{\partial J}{\partial \varepsilon} \frac{\partial \varepsilon}{\partial Y_{p}} \frac{\partial Y_{p}}{\partial K_{p}} \\
& \qquad \frac{\partial J}{\partial \varepsilon}=\varepsilon \frac{\partial \varepsilon}{\partial Y_{p}}=1
\end{aligned}
$$

Parameters $K_{p}$ and $K_{i}$ are determined by applying MIT gradient rules (19).

$$
\begin{aligned}
& \frac{d K_{p}}{d t}=-\gamma_{p} \frac{\partial J}{\partial K_{p}}=-\gamma_{p}\left(\frac{\partial J}{\partial \varepsilon}\right)\left(\frac{\partial \varepsilon}{\partial Y_{p}}\right)\left(\frac{\partial Y_{p}}{\partial K_{p}}\right) \\
& \frac{d K_{i}}{d t}=-\gamma_{i} \frac{\partial J}{\partial K_{i}}=-\gamma_{i}\left(\frac{\partial J}{\partial \varepsilon}\right)\left(\frac{\partial \varepsilon}{\partial Y_{p}}\right)\left(\frac{\partial Y_{p}}{\partial K_{i}}\right)
\end{aligned}
$$

Where, $\partial J / \partial \varepsilon=\varepsilon, \partial \varepsilon / \partial y=1$

$$
\begin{aligned}
& \frac{\partial Y_{p}}{\partial K_{p}}=\left(R(s)-Y_{p}(s)\right) \\
& \left(a_{1} s^{3}+\left(a_{2}-b_{1} K_{d}-b_{1} K_{p}\right) s^{2}+\left(b_{1} s+b_{2}\right) s\right. \\
& \frac{\partial Y_{p}}{\partial K_{i}}=\left(R(s)-Y_{p}(s)\right)
\end{aligned}
$$$$
\frac{-b_{1} s+b_{2}}{\left(a_{1} s^{3}+\left(a_{2}-b_{1} K_{d}-b_{1} K_{p}\right) s^{2}+\left(a_{2}+b_{2} K_{d}-b_{1} K_{i}+b_{2} K_{p}\right) s+b_{2} K_{i}\right)}
$$

From equation (20)
$\frac{d K_{p}}{d t}=-\gamma_{p} \frac{\partial J}{\partial K_{p}}$

$$
=-\gamma_{p} \varepsilon\left(R(s)-Y_{p}(s)\right)
$$

$\frac{\left(-b_{1} s+b_{2}\right) s}{\left(a_{1} s^{3}+\left(a_{2}-b_{1} K_{d}-b_{1} K_{p}\right) s^{2}+\left(a_{2}+b_{2} K_{d}-b_{1} K_{i}+b_{2} K_{p}\right) s+b_{2} K_{i}\right)}$

$\frac{d K_{i}}{d t}=-\gamma_{i} \frac{\partial J}{\partial K_{i}}$

$$
=-\gamma_{i} \varepsilon\left(R(s)-Y_{p}(s)\right)
$$

$\frac{-b_{1} s+b_{2}}{\left(a_{1} s^{3}+\left(a_{2}-b_{1} K_{d}-b_{1} K_{p}\right) s^{2}+\left(a_{2}+b_{2} K_{d}-b_{1} K_{i}+b_{2} K_{p}\right) s+b_{2} K_{i}\right)}$ 


$$
b_{1}, b_{2}, a_{1} \text {, and } a_{2} \text { have an unknown number. }
$$

\section{RESEARCH METHOD}

The research is based on the output voltage generated by the boost converter which has not been properly regulated. This problem occurs when there are changes in input voltage, reference voltage, and the load. This research that will be carried out in a boost converter using a PID controller and a boost converter simulation using DMRAC. The conventional controller PID is utilized to compare the proposed controller that verified by varying input voltage. Table 1 presents the parameters of boost converter.

\begin{tabular}{lll}
\multicolumn{2}{c}{ Table 1. DC-DC boost converter parameters } \\
\hline Parameter & Symbol & Value \\
\hline Input Voltage & $V_{\text {in }}$ & $12 \mathrm{~V}$ \\
Inductance & $L$ & $4.7 \mathrm{mH}$ \\
Resistance & $R$ & $100 \Omega$ \\
Capacitance & $C$ & $470 \mu \mathrm{F}$ \\
\hline
\end{tabular}

By using these pasameters, the model of DC-DC boost converter (5) is utilized as a plant of the system. The derivation DMRAC based on PI controller obtain (22) and (23), these equations are the adaptive controller model. The value of gammas is specified to achieve the appropriate response. Some scenarios for changing the input voltage and load are set to find out the response of the proposed controller.

\section{RESULTS AND ANALYSIS}

The performance of boost converter in proposed controller is proven in simulation such that any changed responses are able to be observed. The input voltage and resistor load of boost converter are $12 \mathrm{~V}$ and $100 \Omega$, respectively. Reference voltage is set to be $48 \mathrm{~V}$ and the value of gammas as following,

$$
\begin{aligned}
& \gamma_{p}=-2 \times 10^{3} \\
& \gamma_{i}=-7 \times 10^{5}
\end{aligned}
$$

The comparison of conventional PID and adaptive PI in boost converter is shown in Figure 3 and Figure 4. Increasing of the input voltage from $12 \mathrm{~V}$ to $24 \mathrm{~V}$ at $0.3 \mathrm{~s}$ makes the little oscillation in output voltage. The proposed controller can reach steady state less than $0.03 \mathrm{~s}$ with a slight overshoot. The transient response of proposed controller has a good response and same response to reference model. In Figure 3, tension stress of proposed controller is more stable even though the $V_{\text {in }}$ is changed at $0.3 \mathrm{~s}$. The conventional PID needs $0.06 \mathrm{~s}$ toward the reference model when there is an increase in the input voltage.

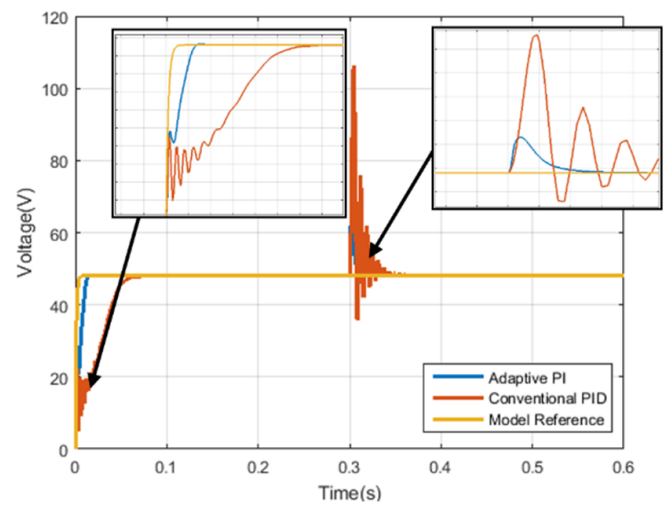

Figure 3. Output voltage rensponse of DC-DC boost converter with changing input voltage 


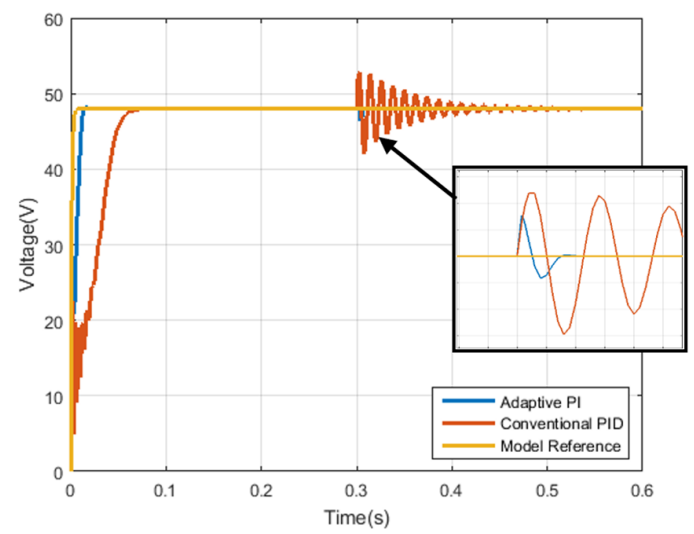

Figure 4. Output voltage rensponse of DC-DC boost converter with changing load

In second scenario, the load is changed to $300 \Omega$ at $0.3 \mathrm{~s}$, a small oscillation occurs and finally follows the reference model. The transient response of the proposed controller shows it has fast response to achieve the voltage reference, the load change makes conventional PID requires more time. The voltage deviation in proposed controller by $6.25 \%$ for $0.01 \mathrm{~s}$, this response is quite fast than conventional PID controller. The output voltage of the changing load is shown in Figure 4. However, the proposed controller has shorter oscilation compared to conventional PID controller, the voltage deviation in less than PID controller.

\section{CONCLUSION}

In this paper, DMRAC is chosen for controlling DC-DC boost converter, this method is satisfied for its controller structure and good performance in various input voltages and loads. The proposed system is stable and able to reach model reference perfectly with shorter recovery time. However, the response of the system has instantaneously overshoot and voltage deviation. The rise time, settling time, and overshoot for step response to follow the response of model reference are some objectives that determine whether the adaptation gains work properly. The adaptation gains determine the success of adaptive control. The adaptation gains of the proposed controller are obtained by empirical gains.

\section{ACKNOWLEDGEMENTS}

The research project was supported by Universitas Brawijaya through Lembaga Penelitian dan Pengabdian Masyarakat Universitas Brawijaya (LPPM - UB).

\section{REFERENCES}

[1] Mostafa Mosa, Mohammad B. Shadmand, Robert S. Balog, Haitham Abu Rub, "Efficient maximum power point tracking using model predictive control for photovoltaic systems under dynamic weather condition", Renewable Power Generation IET, vol. 11, no. 11, pp. 1401-1409, 2017.

[2] Tedjani Mesbahi, Nassim Rizoug, Fouad Khenfri, Patrick Bartholomeüs, Philippe Le Moigne, "Dynamical modelling and emulation of Li-ion batteries-supercapacitors hybrid power supply for electric vehicle applications", Electrical Systems in Transportation IET, vol. 7, no. 2, pp. 161-169, 2017.

[3] Xi Zhang, Chengliang Yin, Hua Bai, "Fixed-boundary-layer Sliding-mode and Variable Switching Frequency Control for a Bidirectional DC-DC Converter in Hybrid Energy Storage System", Electric Power Components and Systems, vol. 45, pp. 1474, 2017.

[4] Hassan Fathabadi, "Plug-in Hybrid Electric Vehicles (PHEVs): Replacing Internal Combustion Engine with Clean and Renewable Energy Based Auxiliary Power Sources", IEEE Transactions on Power Electronics, 2018.

[5] M. Lepanov, Y. Rozanov, "Multifunctional regulator based on SMES and power electronic converter for increase of power quality and power supply reliability", 4th International Conference on Power Engineering Energy and Electrical Drives, pp. 1387-1391, 2013.

[6] C. M. Nirmal Mukundan, P. Jayaprakash, "A new binary hybrid cascaded H-bridge multi level converter for power quality applications", Proc. IEEE 7th Power India International Conference (PIICON), pp. 1-6, Nov. 2016.

[7] Manoranjan Sahoo, Siva Kumar K, "High Gain Step Up DC-DC Converter for DC Micro-Grid Application", Information and Automation for Sustainability (ICIAfS) 2014 7th International Conference, 2014. 
[8] R. K. Subroto, L. Ardhenta, and E. Maulana, "A novel of adaptive sliding mode controller with observer for DC/DC boost converters in photovoltaic system”, 2017 5th International Conference on Electrical, Electronics and Information Engineering (ICEEIE), pp. 9-14, 2017.

[9] M. Forouzesh, Y. P. Siwakoti, S. A. Gorji, F. Blaabjerg, B. Lehman, "Step-Up DC-DC Converters: A Comprehensive Review of Voltage-Boosting Techniques Topologies and Applications", IEEE Transactions on Power Electronics, vol. 32, no. 12, pp. 9143-9178, Dec 2017.

[10] Muhammad H. Rashid, "Power Electronics - Circuits, Devices and Applications", 3rd ed., Prentice Hall of India.

[11] Mohan N., Undeland T. M., and Robbins W. P., "Power Electronics: Converters, Applications, and Design", New York: Wiley, 1995.

[12] Weichao Sun, Yifu Zhang, Yuping Huang, Huijun Gao, Okyay Kaynak, "Transient-Performance-Guaranteed Robust Adaptive Control and Its Application to Precision Motion Control Systems", Industrial Electronics IEEE Transactions on, vol. 63, no. 10, pp. 6510-6518, 2016.

[13] Jianfeng Liao, Zheng Chen, Bin Yao, "Performance-Oriented Coordinated Adaptive Robust Control for FourWheel Independently Driven Skid Steer Mobile Robot", Access IEEE, vol. 5, pp. 19048-19057, 2017.

[14] Chien-Chih Weng, Wen-Shyong Yu, "Hळ tracking adaptive fuzzy integral sliding mode control for parallel manipulators", Systems Man and Cybernetics (SMC) 2010 IEEE International Conference on, pp. 4197-4204, 2010.

[15] Abhishek Nayak, Bidyadhar Subudhi, "Discrete backstepping control of magnetic levitation system with a nonlinear state estimator", India Conference (INDICON) 2016 IEEE Annual, pp. 1-5, 2016.

[16] M. Hashemi, J. Askari, J. Ghaisari, M. Kamali, "Adaptive controller design for nonlinear systems with timevarying state delays", Electrical Engineering (ICEE) 2014 22nd Iranian Conference on, pp. 1197-1202, 2014.

[17] Z.-J. Yang, K. Kunitoshi, S. Kanae, and K. Wada, "Adaptive robust output-feedback control of a magnetic Levitation system by K-filter approach,” IEEE Trans. Ind. Electron, vol. 55, no. 1, pp. 390-399, Jan. 2008.

[18] Chih-Min Lin, Ming-Hung Lin, Chun-Wen Chen, "SoPC-Based Adaptive PID Control System Design for Magnetic Levitation System", Systems Journal IEEE, vol. 5, no. 2, pp. 278-287, 2011.

[19] K. H. Ang, G. Chong, and Y. Li, "PID control system analysis, design, and technology," IEEE Transactions on Control System Technology, vol. 13, no. 4, pp. 559-576, July 2005.

[20] D. E. Seborg, T.F. Edgar and D.A. Mellichamp, "Process Dynamic and Control", 2nd edition, Wiley: New York, 2004.

[21] B. W. Bequett, "Process Control Modelling and Simulation", New Jersy: Prentice- Hall, 2003.

[22] E. Lavretsky and K. A. Wise, "Robust and adaptive control: With aerospace applications, ser. Advanced textbooks in control and signal processing", London and New York: Springer, 2013.

[23] M. Krstic, I. Kanellakopoulos, and P. V. Kokotovic, "Nonlinear and adaptive control design”, New York: Wiley, 1995.

[24] P. C. Parks, "Liapunov Redesign of Model Reference Adaptive Control Systems", IEEE Transaction on Automatic Control, vol-11, no. 6, 1966.

[25] Zhuoyun Nie, Dongsheng Guo, Qingguo Wang, Ruijuan Liu, Laicheng Yan, "Analysis and design of extended state observer with reference model", Control and Decision Conference (CCDC) 2016 Chinese, pp. 589-594, 2016.

\section{BIOGRAPHIES OF AUTHORS}

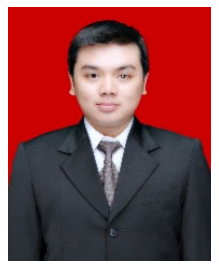

Lunde Ardhenta was born in East Java Province, Indonesia, in 1988. He is currently a junior lecturer at Department of Electrical Engineering, University of Brawijaya, Indonesia. He received the M.S. degree in Department of Electrical Engineering, National ChiaYi University, Taiwan in 2015. He completed his Bachelor degree in Department of Electrical Engineering, University of Brawijaya, Indonesia in 2011. His research interests include renewable energy applications, linear control and digitalized control techniques, and power electronics.

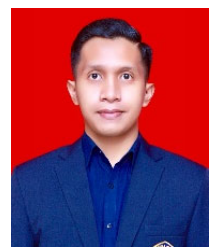

Ramadhani Kurniawan Subroto received B.Eng degree in Electrical Engineering from Sepuluh Nopember Instutute of Technology, Surabaya, Indonesia in 2012 and the M.Eng and M.Sc degrees from Sepuluh Nopember Instutute of Technology and National Taiwan University of Science and Technology, Taipei, Taiwan in 2014. He is currently a lecturer in Brawijaya University, Malang, Indonesia. His research interests include power converters modelling and control, nonlinear control, adaptive control, and power quality. 